\title{
Rare and Nonexistent Nitrosyls: Periodic Trends and Relativistic Effects in Ruthenium and Osmium Porphyrin-Based $\{\mathrm{MNO}\}^{7}$ Complexes
}

Taye B. Demissie, ${ }^{*}, \dagger, \S_{\odot}$ Jeanet Conradie, ${ }^{\dagger, \| \odot ~ H u g o ~ V a z q u e z-L i m a, ~}{ }^{\dagger}$ Kenneth Ruud, $^{\dagger, \ddagger}$ and Abhik Ghosh* ${ }^{*}+$ (0)

${ }^{\dagger}$ Department of Chemistry and ${ }^{\ddagger}$ Hylleraas Centre for Quantum Molecular Sciences, University of Tromsø-The Arctic University of Norway, N-9037 Tromsø, Norway

${ }^{\S}$ Materials Science Program, Department of Chemistry, Addis Ababa University, Addis Ababa, Ethiopia

"Department of Chemistry, University of the Free State, P.O. Box 339, 9300 Bloemfontein, Republic of South Africa

Supporting Information

ABSTRACT: Relativistic and nonrelativistic density functional theory calculations were used to investigate rare or nonexistent ruthenium and osmium analogues of nitrosylhemes. Strong ligand field effects and, to a lesser degree, relativistic effects were found to destabilize $\{\mathrm{RuNO}\}^{7}$ porphyrins relative to their $\{\mathrm{FeNO}\}^{7}$ analogues. Substantially stronger relativistic effects account for the even greater instability and/or nonexistence of $\{\mathrm{OsNO}\}^{7}$ porphyrin derivatives.

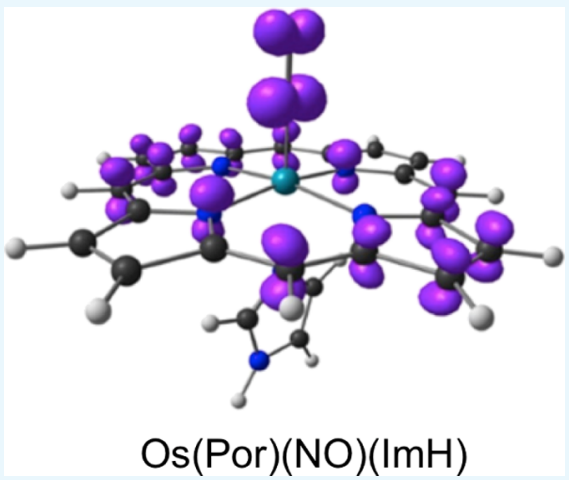

\section{INTRODUCTION}

"Compounds whose structures do not offend the normal rules of valence, but which are nevertheless characterized by a low degree of stability", reviewed by Dasent over a half-century ago, ${ }^{1,2}$ continue to fascinate chemists. ${ }^{3}$ The ruthenium and osmium analogues of nitrosylhemes ${ }^{4,5}$ arguably provide paradigmatic examples of such species. Transition-metal nitrosyls $^{6-10}$ are conveniently described in terms of the Enemark-Feltham notation, ${ }^{11}$ which assigns an effective $d$ electron count to a metal center and consists of the sum of the numbers of metal $\mathrm{d}$ and $\mathrm{NO} \pi^{*}$ electrons. According to this notation, nitrosylheme is an $\{\mathrm{FeNO}\}^{7}$ complex, which may be formally thought of as derived from $\mathrm{Fe}(\mathrm{II}), \mathrm{a} \mathrm{d}^{6}$ ion, and $\mathrm{NO}^{\bullet}$. Unlike nitrosylhemes, which are stable and widespread in both biology and coordination chemistry, analogous $\{\mathrm{RuNO}\}^{7}$ porphyrin species have only been characterized in solution as electrogenerated species ${ }^{12-14}$ and genuine $\{\mathrm{OsNO}\}^{7}$ porphyrins, to our knowledge, remain unknown. ${ }^{15}$ In a similar vein, only a small handful of nonporphyrin $\left\{\mathrm{RuNO}^{7}\right.$ and $\{\mathrm{OsNO}\}^{7}$ species have been reported, generally only as solution-state species. ${ }^{16-23}$ Presented herein is a density functional theory (DFT) study aimed at explaining the rarity and instability of $\left\{\mathrm{RuNO}^{7}\right.$ and $\{\mathrm{OsNO}\}^{7}$ porphyrins. In particular, we have sought to determine whether relativistic effects ${ }^{24}$ play a significant role in influencing the stability of these species.
Given that there is no such thing as a nonrelativistic reality, relativistic effects by definition are purely theoretical quantities. For a given property, the relativistic effect consists of the difference between a value calculated at an adequately high level of relativistic theory and that calculated with an analogous nonrelativistic theory. Over a series of studies on porphyrinoid complexes involving group $6,^{25-27} 7,,^{28,29} 8,,^{30-32}$ and $11^{33-35}$ elements, we and others have found that, for the $5 \mathrm{~d}$ elements, relativistic effects affect redox potentials by up to a few hundred $\mathrm{mV}$ and $\mathrm{UV}-$ vis absorption maxima by several tens of $\mathrm{nm}$; relativistic effects on the analogous $4 \mathrm{~d}$ complexes are by comparison much smaller. Here, we have used relativistic and nonrelativistic DFT calculations on two series of $\{\mathrm{MNO}\}^{7}$ porphyrins, viz., the five-coordinate (5c) $\mathrm{M}$ (Por)(NO) series and the six-coordinate $(6 \mathrm{c}) \mathrm{M}(\mathrm{Por})(\mathrm{NO})(\mathrm{ImH})$ series $(\mathrm{M}=$ $\mathrm{Fe}, \mathrm{Ru}, \mathrm{Os} ;$ Por $=$ porphyrinato; $\mathrm{ImH}=$ imidazole $)$, to assess the importance of nonrelativistic ligand field effects and relativistic effects to the relative stabilities of the complexes.

\section{RESULTS AND DISCUSSION}

The BP86 $6^{36,37}-\mathrm{D} 3^{38} /$ STO-TZ2P and B3LYP ${ }^{36,39,40}$-D3/STOTZ2P optimized geometries of the molecules do not warrant a

Received: June 24, 2018

Accepted: August 14, 2018

Published: September 5, 2018 
Table 1. Scalar-Relativistic (rel) and Nonrelativistic (nrel) Structural Parameters ( $\AA$, deg) for the Five- (5c) and SixCoordinate (6c) Complexes Obtained from BP86-D3/TZ2P (without Parentheses) and B3LYP-D3/TZ2P (in Parentheses) Geometry Optimizations

\begin{tabular}{|c|c|c|c|c|c|c|}
\hline \multirow[b]{2}{*}{$5 c$} & \multicolumn{2}{|c|}{$\mathrm{Fe}($ Por $)(\mathrm{NO})$} & \multicolumn{2}{|c|}{$\mathrm{Ru}$ (Por)(NO) } & \multicolumn{2}{|c|}{ Os(Por)(NO) } \\
\hline & nrel & rel & nrel & rel & nrel & rel \\
\hline $\mathrm{M}-\mathrm{N}(\mathrm{NO})$ & $1.698(1.796)$ & $1.690(1.792)$ & $1.827(1.831)$ & $1.811(1.808)$ & $1.862(1.866)$ & $1.807(1.809)$ \\
\hline $\mathrm{N}-\mathrm{O}$ & $1.176(1.164)$ & $1.177(1.170)$ & $1.183(1.167)$ & $1.187(1.177)$ & $1.185(1.171)$ & 1.197 (1.189) \\
\hline $\mathrm{M}-\mathrm{N} 1$ & $1.998(2.009)$ & $1.993(2.007)$ & $2.062(2.069)$ & $2.053(2.060)$ & $2.081(2.078)$ & $2.052(2.061)$ \\
\hline $\mathrm{M}-\mathrm{N} 2$ & $2.026(2.026)$ & $2.021(2.024)$ & $2.082(2.086)$ & $2.072(2.078)$ & $2.091(2.088)$ & $2.070(2.073)$ \\
\hline \multirow[t]{2}{*}{$\angle \mathrm{M}-\mathrm{N}-\mathrm{O}$} & $144.6(140.9)$ & $144.6(141.2)$ & $139.9(140.6)$ & $140.8(140.5)$ & $138.7(138.5)$ & $143.8(142.4)$ \\
\hline & \multicolumn{2}{|c|}{$\mathrm{Fe}(\mathrm{Por})(\mathrm{NO})(\mathrm{ImH})$} & \multicolumn{2}{|c|}{$\mathrm{Ru}($ Por $)(\mathrm{NO})$} & \multicolumn{2}{|c|}{$\mathrm{Os}(\mathrm{Por})(\mathrm{NO})(\mathrm{ImH})$} \\
\hline $6 c$ & nrel & rel & nrel & rel & nrel & rel \\
\hline $\mathrm{M}-\mathrm{N}(\mathrm{NO})$ & $1.739(1.791)$ & $1.733(1.774)$ & $1.880(1.910)$ & $1.858(1.878)$ & $1.914(1.943)$ & $1.762(1.863)$ \\
\hline $\mathrm{N}-\mathrm{O}$ & $1.181(1.162)$ & $1.182(1.166)$ & $1.186(1.169)$ & $1.188(1.177)$ & $1.186(1.172)$ & $1.176(1.186)$ \\
\hline $\mathrm{M}-\mathrm{N} 1$ & $2.005(2.013)$ & $2.000(2.011)$ & $2.068(2.074)$ & $2.058(2.061)$ & $2.079(2.079)$ & $2.074(2.061)$ \\
\hline $\mathrm{M}-\mathrm{N} 2$ & $2.023(2.024)$ & $2.018(2.027)$ & $2.073(2.077)$ & $2.063(2.072)$ & $2.082(2.083)$ & $2.076(2.068)$ \\
\hline $\mathrm{M}-\mathrm{N}(\mathrm{Im})$ & $2.107(2.078)$ & $2.097(2.102)$ & $2.167(2.179)$ & $2.154(2.177)$ & $2.152(2.157)$ & $2.133(2.174)$ \\
\hline$\angle \mathrm{M}-\mathrm{N}-\mathrm{O}$ & $139.5(138.7)$ & $139.4(139.3)$ & $139.0(141.2)$ & $140.6(139.7)$ & $142.8(140.1)$ & $179.8(143.6)$ \\
\hline
\end{tabular}

great deal of comment (Table 1). The calculations largely reproduce the short, experimentally observed $\mathrm{Fe}-\mathrm{N}(\mathrm{O})$ distances, significantly longer $\mathrm{Fe}-\mathrm{N}(\mathrm{ImH})$ distances (a reflection of the trans influence of $\mathrm{NO}$ ), and FeNO angles of $\sim 140^{\circ}$. The calculations also reproduce (not shown here) the experimentally observed tilting of the $\mathrm{Fe}-\mathrm{N}(\mathrm{O})$ vector relative to the heme normal and the asymmetry of the equatorial $\mathrm{Fe}-$ $\mathrm{N}$ bonds. ${ }^{41,42}$ Although there are no experimental precedents, the heavy element complexes Ru(Por)(NO), $\mathrm{Ru}(\mathrm{Por})(\mathrm{NO})(\mathrm{ImH})$, and $\mathrm{Os}(\mathrm{Por})(\mathrm{NO})$ exhibit the same structural trends. Curiously, scalar-relativistic zeroth-order regular approximation (ZORA) ${ }^{43,44}$ BP86-D3 calculations yield a dramatically anomalous optimized geometry for $\mathrm{Os}(\mathrm{Por})(\mathrm{NO})(\mathrm{ImH})$, characterized by a linear OsNO unit. Analogous scalar-relativistic B3LYP-D3 calculations, on the other hand, yield the expected bent geometry. Another notable point is that the scalar-relativistic BP86-D3 calculations predict a significant shortening of the $\mathrm{Os}-\mathrm{N}(\mathrm{O})$ distance in Os(Por)(NO)(ImH), relative to its 5-coordinated analogue Os(Por)(NO), whereas all the other calculations indicate a lengthening of the $\mathrm{M}-\mathrm{N}(\mathrm{O})$ distance in the presence of the imidazole ligand.

Depending on the functional, the nonrelativistic calculations indicate a modest to substantial lowering of the adiabatic ionization potentials (IPs) for the 5-coordinated series down the group 8 triad, a reflection of the greater ligand field destabilization of $\mathrm{e}_{\mathrm{g}}$-type (in $O_{h}$ symmetry) $4 \mathrm{~d}$ and $5 \mathrm{~d}$ orbitals relative to the $3 \mathrm{~d}$ orbitals (Table 2 ). The sixth ligand also exerts a major influence on the IPs, lowering them by up to an $\mathrm{eV}$, relative to the 5 -coordinated series. By and large,

Table 2. Nonrelativistic (nrel) and Scalar-relativistic (rel) Adiabatic IPs (in eV) of the Complexes Studied: BP86-D3/ TZ2P and B3LYP-D3/TZ2P (within Parentheses)

\begin{tabular}{|lcc|}
\hline \multicolumn{1}{c}{ complexes } & nrel & rel \\
\hline $\mathrm{Fe}($ Por $)(\mathrm{NO})$ & $6.27(6.71)$ & $6.22(6.63)$ \\
$\mathrm{Ru}($ Por $)(\mathrm{NO})$ & $5.92(6.00)$ & $5.79(5.83)$ \\
$\mathrm{Os}($ Por $)(\mathrm{NO})$ & $5.82(5.78)$ & $5.38(5.27)$ \\
$\mathrm{Fe}($ Por $)(\mathrm{NO})(\mathrm{ImH})$ & $5.41(5.81)$ & $5.35(5.79)$ \\
$\mathrm{Ru}($ Por $)(\mathrm{NO})(\mathrm{ImH})$ & $5.06(5.21)$ & $4.91(5.00)$ \\
$\mathrm{Os}($ Por $)(\mathrm{NO})(\mathrm{ImH})$ & $4.79(4.98)$ & $4.69(4.47)$
\end{tabular}

relativistic effects on the IPs proved marginal $(<0.1 \mathrm{eV})$ for $\mathrm{Fe}$, slightly higher for $\mathrm{Ru}(\sim 0.2 \mathrm{eV})$, and substantial $(\sim 0.5 \mathrm{eV})$ for the 5-coordinate Os complex, consistent with the expected relativistic destabilization of the $\mathrm{Os} 5 \mathrm{~d}$ orbitals relative to the $\mathrm{Ru} 4 \mathrm{~d}$ orbitals. Once again, the scalar-relativistic BP86-D3 results on $\mathrm{Os}$ (Por) $(\mathrm{NO})(\mathrm{ImH})$ proved anomalous, predicting a modest $0.1 \mathrm{eV}$ lowering of the adiabatic IP relative to the nonrelativistic BP86-D3 calculations.

An examination of the scalar-relativistic spin density profiles of the complexes studied (Table 3 and Figure 1) provided an

Table 3. Selected Mulliken Spin Populations from ZORA Scalar-relativistic BP86-D3/TZ2P and B3LYP-D3/TZ2P (in Parentheses) Calculations

\begin{tabular}{llcc}
\multicolumn{1}{c}{ complex } & \multicolumn{1}{c}{$\mathrm{M}$} & $\mathrm{N}$ & $\mathrm{O}$ \\
$\mathrm{Fe}($ Por $)(\mathrm{NO})$ & $0.931(0.861)$ & $0.056(0.162)$ & $0.005(0.068)$ \\
$\mathrm{Ru}($ Por $)(\mathrm{NO})$ & $0.575(0.477)$ & $0.213(0.289)$ & $0.124(0.173)$ \\
$\mathrm{Os}($ Por $)(\mathrm{NO})$ & $0.489(0.456)$ & $0.226(0.288)$ & $0.131(0.172)$ \\
$\mathrm{Fe}($ Por $)(\mathrm{NO})(\mathrm{ImH})$ & $0.511(0.194)$ & $0.297(0.503)$ & $0.174(0.297)$ \\
$\mathrm{Ru}($ Por $)(\mathrm{NO})(\mathrm{ImH})$ & $0.175(0.146)$ & $0.421(0.504)$ & $0.262(0.304)$ \\
$\mathrm{Os}($ Por $)(\mathrm{NO})(\mathrm{ImH})$ & $-0.040(0.074)$ & $0.140(0.490)$ & $0.083(0.299)$ \\
\hline
\end{tabular}

explanation for the above anomalous findings. The presence of a sixth ligand in $\{\mathrm{FeNO}\}^{7}$ porphyrins generally drives much of the spin density from the metal to the NO, ${ }^{45,46}$ which is indeed what is observed; the $\mathrm{Ru}$ spin density profiles also reveal the same trend. For Os(Por)(NO)(ImH), on the other hand, the scalar-relativistic spin density profile proved dramatically different, which is consistent with an essentially $\{\text { OsNO }\}^{6}-$ $\mathrm{Por}^{\bullet 3-}$ radical formulation. This computational result nicely parallels experimental observations by Richter-Addo and coworkers, $^{15}$ who concluded on the basis of infrared spectroelectrochemical studies that one-electron reduction of $\mathrm{Os}[\mathrm{OEP}](\mathrm{NO})(\mathrm{SEt})$ (OEP = octaethylporphyrin) initially yields an $\{\mathrm{OsNO}\}^{6}-\mathrm{Por}^{\bullet-}$ radical anion, which subsequently, presumably upon valence tautomerism, loses NO. The $\{\mathrm{OsNO}\}^{6}-\mathrm{Por}^{\bullet-}$ formulation provides a simple explanation for the linearity of the OsNO unit and the short Os-N(O) distance for $\mathrm{Os}(\mathrm{Por})(\mathrm{NO})(\mathrm{ImH})$. 


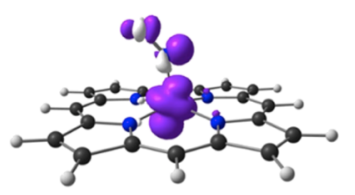

$\mathrm{Fe}(\mathrm{Por})(\mathrm{NO})$

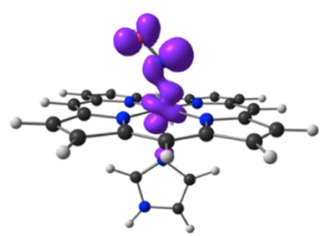

$\mathrm{Fe}(\mathrm{Por})(\mathrm{NO})(\mathrm{ImH})$

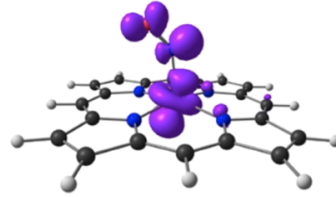

$\mathrm{Ru}(\mathrm{Por})(\mathrm{NO})$

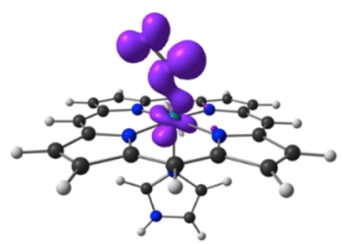

$\mathrm{Ru}(\mathrm{Por})(\mathrm{NO})(\mathrm{ImH})$

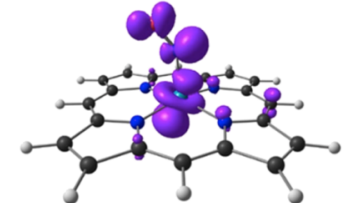

Os(Por)(NO)

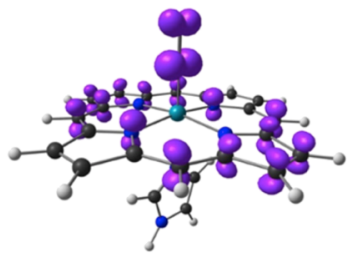

Os(Por)(NO)(ImH)

Figure 1. Scalar-relativistic BP86-D3 spin density plots for the complexes studied. Majority and minority spin densities are shown in purple and ivory, respectively.

\section{CONCLUSIONS}

Low IPs, which translate to low oxidation potentials, provide a partial explanation for the rarity and/or nonexistence of $\{\mathrm{RuNO}\}^{7}$ and $\{\mathrm{OsNO}\}^{7}$ porphyrin complexes. Relativistic effects play a particularly major role in lowering the IPs of potential $\{\text { OsNO }\}^{7}$ species. The sixth ligand plays a critically important role in determining the stability of the species in question: the $\{\mathrm{MNO}\}^{7}$ state may spontaneously lose $\mathrm{NO}$ or otherwise decompose in the presence of strong-field trans ligands such as alkoxide, thiolate, or aryl. The equatorial ligand is also important; thus, whereas electroreduction of certain $\{\mathrm{RuNO}\}^{6}$ porphyrins occurs reversibly and yields $\{\mathrm{RuNO}\}^{7}$ species in solution, ${ }^{12-14}$ electroreduction of $\{\mathrm{RuNO}\}^{6}$ corroles occurs irreversibly, with concomitant loss of NO. ${ }^{32}$ Last but not least, the fact that the BP86-D3 and B3LYP-D3 methods afford radically different electronic descriptions for the sixcoordinate $\{\mathrm{OsNO}\}^{7}$ model complex underscores the need for further methodological investigations for heavy-elementcontaining compounds, especially for open-shell $4 \mathrm{~d}$ and $5 \mathrm{~d}$ transition-metal complexes.

\section{COMPUTATIONAL METHODS}

All calculations were carried out with the Amsterdam Density Functional (ADF 2016) ${ }^{47,48}$ program system (see above for additional details). Relativistic effects were taken into account via the ZORA approximation to the two-component Dirac equation, applied both as a scalar correction and with spinorbit coupling (SOC). For structural parameters and IPs, the SOC results proved essentially identical to those obtained from scalar relativistic calculations; accordingly, only the latter are explicitly tabulated in this paper. Suitably tight convergence criteria were used throughout, as implemented in the ADF program system. Frequency analyses were performed for all optimized geometries to confirm the absence of imaginary frequencies.

\section{ASSOCIATED CONTENT}

\section{S Supporting Information}

The Supporting Information is available free of charge on the ACS Publications website at DOI: 10.1021/acsomega.8b01434.

Optimized Cartesian coordinates (26 pages) (PDF)

\section{AUTHOR INFORMATION}

\section{Corresponding Authors}

*E-mail: sene3095@gmail.com (T.B.D.).

*E-mail: abhik.ghosh@uit.no (A.G.).

ORCID

Taye B. Demissie: 0000-0001-8735-4933

Jeanet Conradie: 0000-0002-8120-6830

Kenneth Ruud: 0000-0003-1006-8482

Abhik Ghosh: 0000-0003-1161-6364

\section{Notes}

The authors declare no competing financial interest.

\section{ACKNOWLEDGMENTS}

This work was supported by grants 262229 and 179568 from the Research Council of Norway and the National Research Fund of the Republic of South Africa.

\section{REFERENCES}

(1) Dasent, W. E. Nonexistent Compounds: Compounds of Low Stability; Marcel Dekker: New York, 1965; pp 1-182.

(2) Dasent, W. E. Non-existent compounds. J. Chem. Educ. 1963, 40, 130-134.

(3) Hoffmann, R. Why Think Up New Molecules? Am. Sci. 2008, 96, $372-374$.

(4) The Smallest Biomolecules: Diatomics and their Interactions with Heme Proteins; Ghosh, A., Ed.; Elsevier, 2008; pp 1-603.

(5) Hunt, A. P.; Lehnert, N. Heme-Nitrosyls: Electronic Structure Implications for Function in Biology. Acc. Chem. Res. 2015, 48, 21172125.

(6) Richter-Addo, G. B.; Legzdins, P. Metal Nitrosyls; Oxford University Press: New York, 1992; pp. 353-384

(7) Wyllie, G. R. A.; Scheidt, W. R. Solid-State Structures of Metalloporphyrin NOx Compounds. Chem. Rev. 2002, 102, 10671090.

(8) Ghosh, A. Metalloporphyrin-NO Bonding: Building Bridges with Organometallic Chemistry. Acc. Chem. Res. 2005, 38, 943-954.

(9) Ghosh, A.; Hopmann, K. H.; Conradie, J. Electronic Structure Calculations: Transition Metal-NO Complexes in Computational Inorganic and Bioinorganic Chemistry, Solomon, E. I.; Scott, R. A.; King, R. B., Eds.; John Wiley \& Sons Ltd: Chichester, UK, 2009; pp. $389-410$.

(10) Mingos, D. M. P. Historical Introduction to Nitrosyl Complexes; Structure and Bonding; Springer, 2014; Vol. 153, pp 1-44.

(11) Enemark, J. H.; Feltham, R. D. Principles of structure, bonding, and reactivity for metal nitrosyl complexes. Coord. Chem. Rev. 1974, $13,339-406$. 
(12) Kadish, K. M.; Adamian, V. A.; van Caemelbecke, E.; Tan, Z.; Tagliatesta, P.; Bianco, P.; Boschi, T.; Yi, G.-B.; Khan, M. A.; RichterAddo, G. B. Synthesis, Characterization, and Electrochemistry of Ruthenium Porphyrins Containing a Nitrosyl Axial Ligand. Inorg. Chem. 1996, 35, 1343-1348.

(13) Singh, P.; Das, A. K.; Sarkar, B.; Niemeyer, M.; Roncaroli, F.; Olabe, J. A.; Fiedler, J.; Zálišs, S.; Kaim, W. Redox Properties of Ruthenium Nitrosyl Porphyrin Complexes with Different Axial Ligation: Structural, Spectroelectrochemical (IR, UV-Visible, and EPR), and Theoretical Studies. Inorg. Chem. 2008, 47, 7106-7113.

(14) Zink, J. R.; Abucayon, E. G.; Ramuglia, A. R.; Fadamin, A.; Eilers, J. E.; Richter-Addo, G. B.; Shaw, M. J. Electrochemical Investigation of the Kinetics of Chloride Substitution upon Reduction of $[\mathrm{Ru}($ porphyrin $)(\mathrm{NO}) \mathrm{Cl}]$ Complexes in Tetrahydrofuran. ChemElectroChem 2018, 5, 861-871.

(15) Carter, S. M.; Lee, J.; Hixson, C. A.; Powell, D. R.; Wheeler, R. A.; Shaw, M. J.; Richter-Addo, G. B. Fiber-optic infrared reflectance spectroelectrochemical studies of osmium and ruthenium nitrosyl porphyrins containing alkoxide and thiolate ligands. Dalton Trans. 2006, 1338-1346.

(16) Callahan, R. W.; Brown, G. M.; Meyer, T. J. Reversible electron transfer to the nitrosyl group in ruthenium nitrosyl complexes. J. Am. Chem. Soc. 1975, 97, 894-895.

(17) Callahan, R. W.; Meyer, T. J. Reversible electron transfer in ruthenium nitrosyl complexes. Inorg. Chem. 1977, 16, 574-581.

(18) Baumann, F.; Kaim, W.; Baraldo, L. M.; Slep, L. D.; Olabe, J. A.; Fiedler, J. Reduction of the $\mathrm{NO}^{+}$ligand in the pentacyanonitrosylosmate(II) ion. Inorg. Chim. Acta 1999, 285, $129-133$.

(19) Wanner, M.; Scheiring, T.; Kaim, W.; Slep, L. D.; Baraldo, L. M.; Olabe, J. A.; Zálǐs, S.; Baerends, E. J. EPR Characteristics of the $\left[(\mathrm{NC})_{5} \mathrm{M}(\mathrm{NO})\right]^{3-}$ Ions $(\mathrm{M}=\mathrm{Fe}, \mathrm{Ru}, \mathrm{Os})$. Experimental and DFT Study Establishing $\mathrm{NO}$ as a Ligand. Inorg. Chem. 2001, 40, 57045707.

(20) Sieger, M.; Sarkar, B.; Zálǐ̌, S.; Fiedler, J.; Escola, N.; Doctorovich, F.; Olabe, J. A.; Kaim, W. Establishing the NO oxidation state in complexes $\left[\mathrm{Cl}_{5}(\mathrm{NO}) \mathrm{M}\right]^{\mathrm{n}-}, \mathrm{M}=\mathrm{Ru}$ or Ir, through experiments and DFT calculations. Dalton Trans. 2004, 1797-1800.

(21) Frantz, S.; Sarkar, B.; Sieger, M.; Kaim, W.; Roncaroli, F.; Olabe, J. A.; Zálišs, S. EPR Insensitivity of the Metal-Nitrosyl SpinBearing Moiety in Complexes $\left[\mathrm{L}_{\mathrm{n}} \mathrm{Ru}^{\mathrm{II}}-\mathrm{NO}^{\bullet}\right]^{\mathrm{k}}$. Eur. J. Inorg. Chem. 2004, 2004, 2902-2907.

(22) Singh, P.; Sarkar, B.; Sieger, M.; Niemeyer, M.; Fiedler, J.; Zálišs, S.; Kaim, W. The Metal-NO Interaction in the Redox Systems $\left[\mathrm{Cl}_{5} \mathrm{Os}(\mathrm{NO})\right]^{\mathrm{n}-}, \mathrm{n}=1-3$, and cis-[(bpy $\left.)_{2} \mathrm{ClOs}(\mathrm{NO})\right]^{2+/+}:$ Calculations, Structural, Electrochemical, and Spectroscopic Results. Inorg. Chem. 2006, 45, 4602-4609.

(23) Lahiri, G. K.; Kaim, W. Electronic structure alternatives in nitrosylruthenium complexes. Dalton Trans. 2010, 39, 4471-4478.

(24) Pyykkö, P. Relativistic effects in chemistry: more common than you thought. Annu. Rev. Phys. Chem. 2012, 63, 45-64.

(25) Alemayehu, A. B.; Vazquez-Lima, H.; Gagnon, K. J.; Ghosh, A. Tungsten Biscorroles: New Chiral Sandwich Compounds. Chem.Eur. J. 2016, 22, 6914-6920.

(26) Alemayehu, A. B.; Vazquez-Lima, H.; McCormick, L. J.; Ghosh, A. Relativistic effects in metallocorroles: comparison of molybdenum and tungsten biscorroles. Chem. Commun. 2017, 53, 5830-5833.

(27) Schies, C.; Alemayehu, A. B.; Vazquez-Lima, H.; Thomas, K. E.; Bruhn, T.; Bringmann, G.; Ghosh, A. Relativistic effects in metallocorroles: comparison of molybdenum and tungsten biscorroles. Chem. Commun. 2017, 53, 5830-5833.

(28) Einrem, R. F.; Braband, H.; Fox, T.; Vazquez-Lima, H.; Alberto, R.; Ghosh, A. Synthesis and Molecular Structure of ${ }^{99} \mathrm{Tc}$ Corroles. Chem.-Eur. J. 2016, 22, 18747-18751.

(29) Einrem, R. F.; Gagnon, K. J.; Alemayehu, A. B.; Ghosh, A. Metal-Ligand Misfits: Facile Access to Rhenium-Oxo Corroles by Oxidative Metalation. Chem.-Eur. J. 2016, 22, 517-520.

(30) Liao, M.-S.; Scheiner, S. Relativistic effects in iron-, ruthenium-, and osmium porphyrins. Chem. Phys. 2002, 285, 195-206.
(31) Alemayehu, A. B.; Gagnon, K. J.; Terner, J.; Ghosh, A. Oxidative Metalation as a Route to Size-Mismatched Macrocyclic Complexes: Osmium Corroles. Angew. Chem., Int. Ed. 2014, 53, 14411-14414.

(32) Alemayehu, A. B.; Vazquez-Lima, H.; Gagnon, K. J.; Ghosh, A. Stepwise Deoxygenation of Nitrite as a Route to Two Families of Ruthenium Corroles: Group 8 Periodic Trends and Relativistic Effects. Inorg. Chem. 2017, 56, 5285-5294.

(33) Schwerdtfeger, P. Relativistic effects in properties of gold. Heteroat. Chem. 2002, 13, 578-584.

(34) Pyykkö, P. Theoretical chemistry of gold. III. Chem. Soc. Rev. 2008, 37, 1967-1997.

(35) Thomas, K. E.; Vazquez-Lima, H.; Fang, Y.; Song, Y.; Gagnon, K. J.; Beavers, C. M.; Kadish, K. M.; Ghosh, A. Ligand Noninnocence in Coinage Metal Corroles: A Silver Knife-Edge. Chem.-Eur. J. 2015, $21,16839-16847$.

(36) Becke, A. D. Density-functional exchange-energy approximation with correct asymptotic behavior. Phys. Rev. A: At., Mol., Opt. Phys. 1988, 38, 3098-3100.

(37) Perdew, J. P. Density-functional approximation for the correlation energy of the inhomogeneous electron gas. Phys. Rev. B: Condens. Matter Mater. Phys. Rev. B: Condens. Matter Mater. Phys. 1986, 33, 8822-8824;Perdew, J. P. Erratum. Phys. Rev. B: Condens. Matter Mater. Phys. Rev. B: Condens. Matter Mater. Phys. 1986, 34, 7406.

(38) Grimme, S.; Antony, J.; Ehrlich, S.; Krieg, H. A consistent and accurate $\mathrm{ab}$ initio parametrization of density functional dispersion correction (DFT-D) for the 94 elements H-Pu. J. Chem. Phys. 2010, $132,154104$.

(39) Lee, C.; Yang, W.; Parr, R. G. Development of the ColleSalvetti correlation-energy formula into a functional of the electron density. Phys. Rev. B: Condens. Matter Mater. Phys. 1988, 37, 785-789.

(40) Stephens, P. J.; Devlin, F. J.; Chabalowski, C. F.; Frisch, M. J. $\mathrm{Ab}$ Initio Calculation of Vibrational Absorption and Circular Dichroism Spectra Using Density Functional Force Fields. J. Phys. Chem. 1994, 98, 11623-11627.

(41) Scheidt, W. R.; Duval, H. F.; Neal, T. J.; Ellison, M. K. Intrinsic Structural Distortions in Five-Coordinate (Nitrosyl)iron(II) Porphyrinate Derivatives. J. Am. Chem. Soc. 2000, 122, 4651-4659.

(42) Ghosh, A.; Wondimagegn, T. A Theoretical Study of Axial Tilting and Equatorial Asymmetry in Metalloporphyrin-Nitrosyl Complexes. J. Am. Chem. Soc. 2000, 122, 8101-8102.

(43) van Lenthe, E.; Baerends, E. J.; Snijders, J. G. Relativistic regular two-component Hamiltonians. J. Chem. Phys. 1993, 99, 45974610.

(44) van Lenthe, E.; Baerends, E. J.; Snijders, J. G. Relativistic total energy using regular approximations. J. Chem. Phys. 1994, 101, 97839792.

(45) Tangen, E.; Svadberg, A.; Ghosh, A. Toward modeling H-NOX domains: A DFT study of heme-NO complexes as hydrogen bond acceptors. Inorg. Chem. 2005, 44, 7802-7805.

(46) Praneeth, V. K. K.; Haupt, E.; Lehnert, N. Thiolate coordination to $\mathrm{Fe}(\mathrm{II})$-porphyrin $\mathrm{NO}$ centers. J. Inorg. Biochem. 2005, 99, 940-948.

(47) The ADF program system uses methods described in: te Velde, G.; Bickelhaupt, F. M.; Baerends, E. J.; Guerra, C. F.; van Gisbergen, S. J. A.; Snijders, J. G.; Ziegler, T. Chemistry with ADF. Comput. Chem. 2001, 22, 931-967.

(48) For additional details on all aspects of the calculations, see the ADF program manual: http://www.scm.com/ADF/. 